\title{
MORE REAL: Collecting Studio Culture Confessions and Successes
}

\author{
ERIKA LINDSAY \\ University of Detroit Mercy
}

EMILY KUTIL

University at Buffalo

MORE REAL explores the question of "studio culture" in architecture schools. The authors conducted a survey of architecture faculty during the Fall 2019 ACSA Conference, Less Talk | More Action, which asked respondents, "What is your experience of studio culture?" The following paper discusses the design of the survey and conference engagement, analyzes the quantitative (demographic data and data about the respondent's position within the school) and qualitative (response to the "studio culture" question) information gathered in the survey, and discusses the MORE REAL session hosted at the ACSA conference. The authors identify a range of consistent themes that emerged in the survey responses and discuss the implications of those themes. Finally, the authors outline strategies for refining and expanding the survey design, as well as strategies for reaching a more representative set of survey participants in future iterations of MORE REAL.

\section{INTRODUCTION}

As instructors, we design our studios. We set the tone, control the pace, and shape studio culture. But few studio professors have received formal training in teaching methods, and we often find ourselves replicating the flawed models we experienced when we were students. While we regularly discuss project structures and course content with our colleagues, we rarely consider how we teach: the social dynamics we foster in our studios and the relationships we build with our students. If our goal as studio instructors is to foster positive studio environments where students feel ownership, agency, and support, we must explicitly consider studio culture as a defining component of our pedagogy.

The ideas explored in this study emerged from informal conversations about the authors' own experiences teaching studio. Between classes, we would discuss our relationships with our students, our students' social dynamics, and mental health questions. We would discuss our successes and failures, the things we learn through experience, and the situations we don't quite know how to handle. The authors see MORE REAL as an opportunity to open up a conversation between a wider range of studio instructors and students, to support a culture of honest and vulnerable dialogue about what is and isn't working in our studios. In this paper, we discuss our first MORE REAL survey, completed during the 2019 ACSA fall conference, Less
Talk | More Action. We describe the survey design, the results of our workshop at the ACSA conference, and the responses we collected. We analyze the results of this engagement, and we identify opportunities to refine the survey and to engage broader groups of instructors and students.

\section{SURVEY DESIGN}

To begin, we created a survey to ask our colleagues the same question we had been asking each other: what is your experience of studio culture? In the responses, we were interested in learning about both the respondents' specific experiences and the respondents' interpretation of the term "studio culture" itself. The survey itself is simple (Figure 1), with only one short answer question, since we understood that a simple survey would elicit more responses. We wanted the survey to be inclusive, open-ended, and accessible via multiple platforms. We made physical postcards and submission boxes for the Less Talk | More Action conference, along with an online form. We promoted the project with a website, an Instagram account, and personal emails. A consistent graphic identity creates continuity across the project's multiple platforms. In designing MORE REAL, we considered other, future iterations of the survey and further engagement around the project.

In the survey, we also collected demographic data and data about the respondent's position within the school (Figure 2). Because we want to understand studio culture from the perspectives of a wide range of people that experience it (both faculty and students), we felt we needed to understand who was answering the survey. We wanted to see if any patterns would emerge between demographics, positions, and experiences. We understand that race/ethnicity, socioeconomic status, gender, and sexuality influence our experiences in fundamental ways, on structural and interpersonal levels.

\section{QUANTITATIVE RESPONSES}

The first phase of the MORE REAL survey garnered 34 responses. Compared to the number of faculty members teaching architecture in the United States (5,887 full-time, part-time, and adjunct faculty in 2018), ${ }^{1}$ this number is not statistically significant. But the responses are nevertheless instructive. They offer an initial set of data from which to work, and they indicate ways in which we can refine and expand the study in future iterations. 


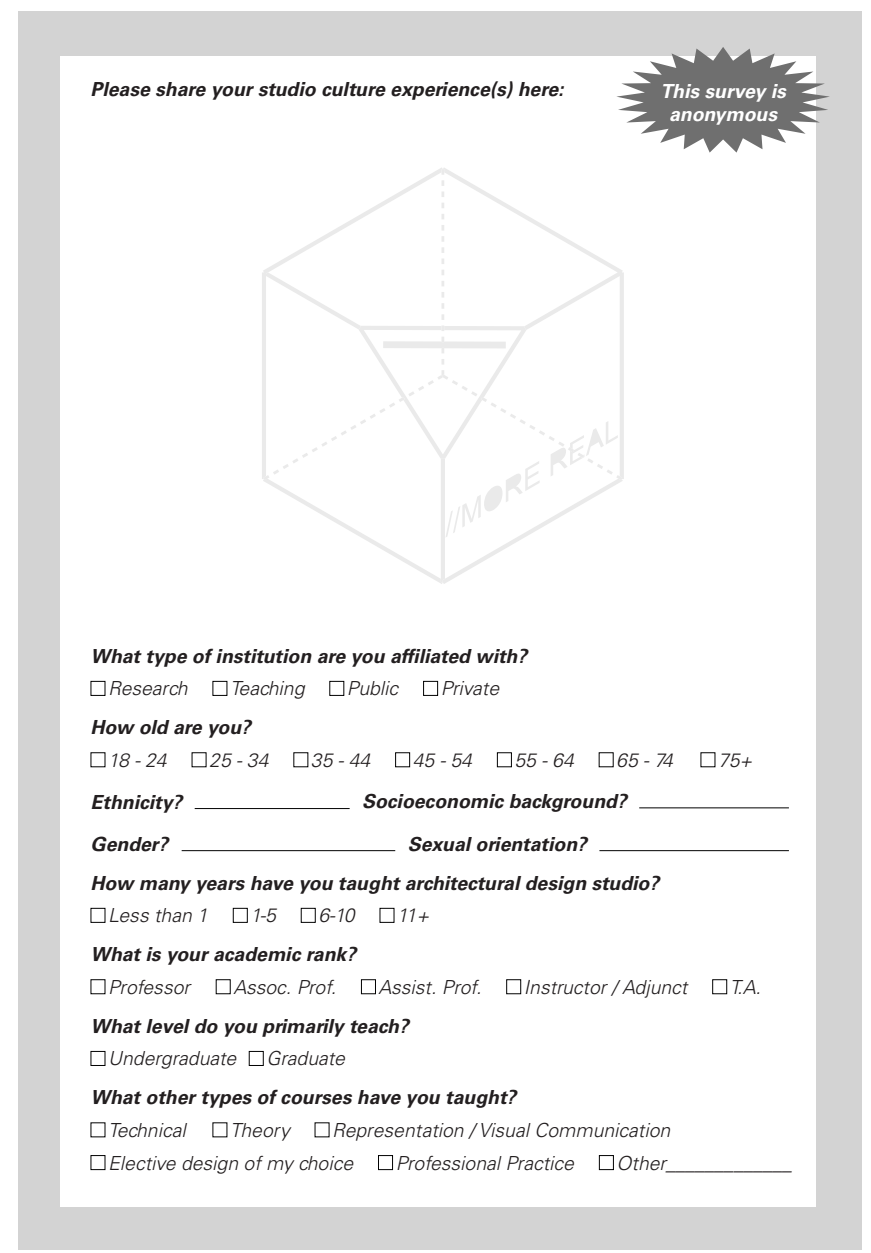

Figure 1: The MORE REAL Survey.

Analysis of the demographic data shows that most respondents describe themselves as female (68\%), white (71\%), heterosexual (74\%), and from a "middle class" socioeconomic background (50\%). This demographic data largely aligns with larger demographic trends in architecture faculty in the United States ${ }^{2}$, except that a disproportionate number of female faculty members responded to the survey. While women make up $31 \%$ of full-time and part-time architecture faculty nationally, more than double that percentage of survey respondents describe themselves as female. ${ }^{3}$ The survey respondents represent a fairly even range of experience levels and academic ranks, as well as a range of types of institutions (public, private, teaching-oriented, and research-oriented). Respondents primarily teach at the undergraduate level, or both undergraduate and graduate. Almost all of the survey respondents are faculty members, as we expected based on the ACSA conference attendance; three student teaching assistants also answered the survey.

With a small sample size, it is difficult to identify patterns or draw statistical conclusions about survey responses. But the responses give us important information about the groups we are reaching, and help us to identify gaps. The most obvious gap in respondents is students: because we have primarily reached studio instructors in this first survey, we are missing critically important input from the people studio culture affects most profoundly: the students themselves. The authors are very interested to see how responses will vary between students and faculty. We also see a need to specifically survey underrepresented minority groups among both students and faculty; we expect that this will expose important differences in the studio culture experience. We also expect that expanding the number of faculty members at varying ranks within their schools will present helpful insights about the ways faculty perceive and experience studio culture differently (for example, adjuncts vs. tenured faculty). In the conclusion, we discuss strategies for reaching a more broadly representative group of architecture faculty and students in future surveys.

\section{QUALITATIVE RESPONSES}

Responses to the survey varied widely, both in the themes discussed and in the way the respondents interpreted the survey's core question. The term "studio culture" can mean many things depending on the respondent's experiences. ${ }^{4}$ Although many faculty wrote about their own experiences as an instructor, very few acknowledged or explicitly discussed the role they play as instructors in defining studio culture. Interestingly, many responded by recalling their experiences of being a student. To begin to make sense of the varied responses, we grouped the responses according to themes that have consistently emerged (Figure 3).

Eight respondents brought up themes of competition and/or collaboration. Uniformly, collaboration was described in positive terms: "Safe space for exploration and discovery. Shared learning. Best learning environment for all subjects;" "I do a cooperative teaching method that downplays individual authorship in favor of developing "leadership" or critical skills;" "Taking students camping every fall at the start of the semester has been a great way to build culture and community. We have intentionally integrated a lot of collaborative and communitybased work into our curriculum which has been a great way to break the pattern of individual focus on self-generated design and shift toward work bigger than the self." Several responses characterized competition as detrimental to studio culture: "When I was in school 20 years ago almost all faculty were white and male. They tried to 'weed out' students;" "My experience was extremely competitive." One response described studio as being both competitive and collaborative, suggesting that these dynamics exist alongside one another in the studio: "Studio: intense, collaborative, competitive, exhausting, primary priority, overemphasized, fun." Another described a lack of "healthy competition" in studios where students commute and don't work in the studio outside of studio hours. These different perspectives suggest that there is disagreement among studio instructors about the impacts of competition on studio culture. Future surveys should explore these dynamics further, by asking 


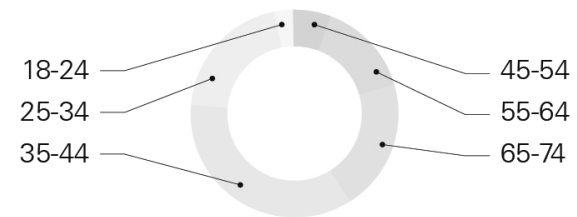

How old are you?

unspecified

african-american

asian

hispanic

white

What is your ethnioity?

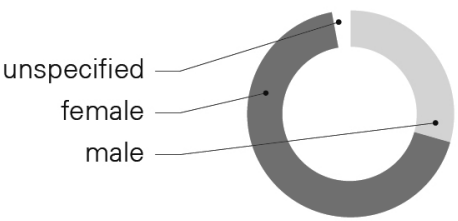

What is your gonder?

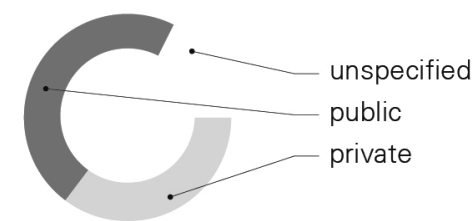

What type of institution are you affiliated with?

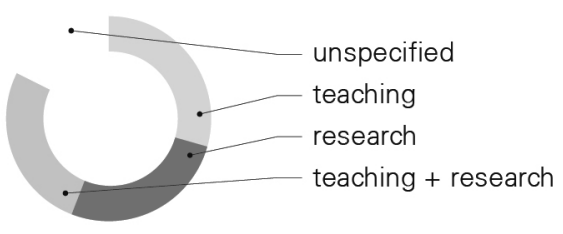

What type of institution are you affiliated with?

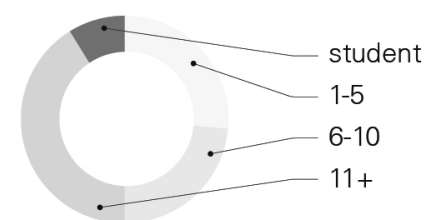

How many years of experienoe do you have teaohing studio?

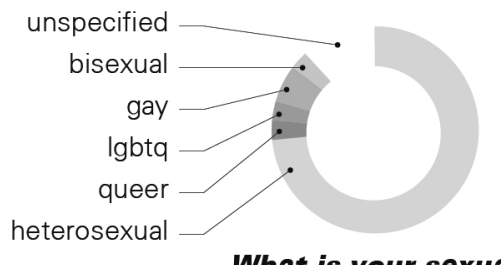

What is your sexual orientation?

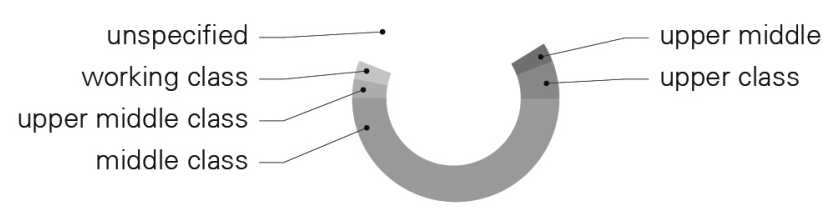

What is your sooioeoonomio baokground?

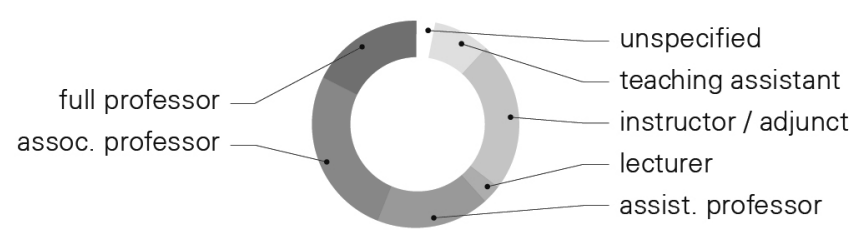

What is your aoademio rank?

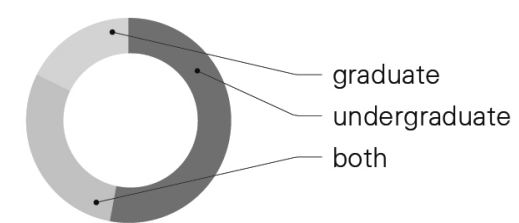

What level do you primarily teach? 


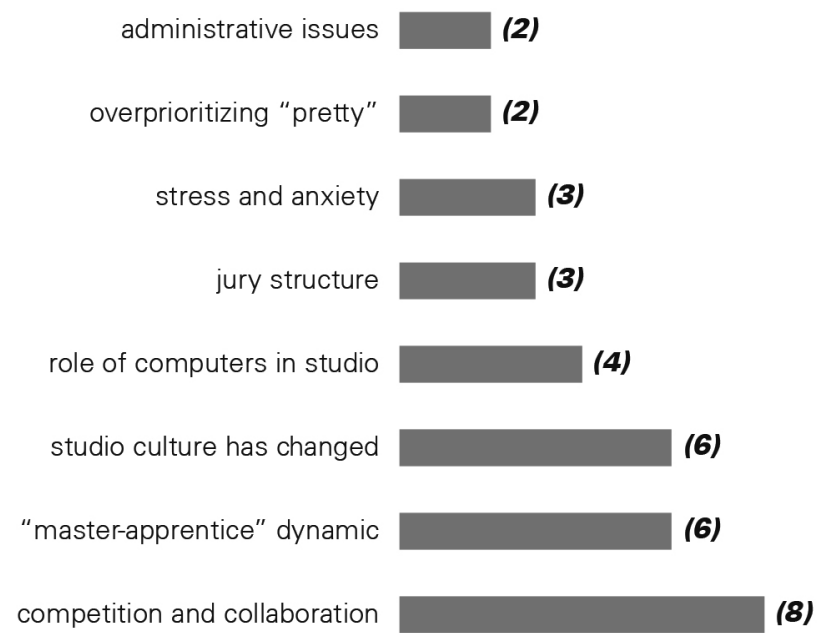

Figure 3: Commonly referenced themes in the survey responses.

specifically about the role competition and collaboration play in the quality of students' experiences. Based on the responses, it is clear that these experiences play important roles in shaping studio culture, and that instructors should carefully consider how they encourage students to either collaborate or compete.

The other most commonly recurring theme was the "masterapprentice" dynamic between instructors and students, which was always described as harmful and problematic. Interestingly, almost all of the responses that brought up the "master-apprentice" paradigm placed responsibility for this dynamic on the students themselves. Some respondents cited student passivity, lack of motivation, or lack of discipline: "I do feel students tend to be passive overall;" "Generally the faculty feels the students aren't motivated and disciplined enough." Others wrote that students expect or want their instructors to direct them, to the detriment of student-to-student collaboration and feedback: "I have found that they are not comfortable asking a peer for input or discussing their work with one another. Rather they go directly to an instructor..." "They were looking to us as instructors for our approval of their design rather than wanting to defend their thoughts informed by their research. Many of the students expressed extreme discontent for the peer desk critiques as they felt they were a waste of time and didn't want their colleagues' feedback;" "Isolated, faculty-centric, master/apprentice paradigm... student-to-student disengagement..." The latter responses suggest that studio instructors should develop methods for encouraging student independence and confidence in critiquing one another. Only one respondent overtly discussed the role instructors play in contributing to "master-apprentice" dynamics: "I think that as professors we need to be acutely aware of how our design aesthetics creep into the studio as to not overstep into their learning process."
Several respondents described the traditional jury review structure as unproductive and detrimental to learning: "Recently I've found jury reviews to be unduly critical and unproductive. Some faculty seem to not focus on helping students improve in this setting..." "The jury is a wall that physically blocks interaction and discussion with the rest of the students as well as isolates and almost cages the student being reviewed;" "Reviews: negative! Terrible! Mostly not constructive." These responses suggest that the jury review structure sets up a negative power relationship between students and critics, encourages (or allows for) unproductive criticism, and both socially and physically isolates the student. While not a single response described the jury review positively, the jury review remains by far the most widely used format for discussing final student work and is deeply embedded within the institutional structure of most architecture schools.

Two respondents discussed an overemphasis on making aesthetically pleasing work, rather than valuing student work in other ways: "pretty and interesting driven;" "Students themselves can have limited understanding (or acceptance) of growth at different paces or in different directions, 'ugly drawings' getting vilified during process development gets paralyzing and prevents complex ideas from getting developed. This is both from general student body, as well as from self-criticism in students themselves. This is supported by critics to varying degrees." These comments suggest a sense of frustration among faculty about pedagogical priorities, and a need to foster more supportive cultures of self- and peercritique among students.

Contrary to the authors' expectations, few respondents discussed the pressures of studio and their impacts on student mental health. Three respondents did write about this topic: "Design studios are an intense and unbalanced period of a person's life;" "Studio: intense, collaborative, competitive, exhausting, primary priority, overemphasized, fun;" "...the stress of thesis, studio, and work definitely kills me. The studio often is packed all night and although it is fun, often leads people into anxiety states." Significantly, one of these responses was written by a student teaching assistant. Two of the respondents write about stress, anxiety, intensity, and fun in the same sentence, a connection that bears further examination. The authors expect a far greater number of students to discuss stress and anxiety in future surveys.

Many respondents discussed external forces, or forces beyond the control of the instructor, that affect studio culture. Two responses described administrative issues. One response, "Pencils down throughout the whole department set before department-wide final review celebration... but some faculty do not enforce. It is pencils down wink, wink," implies a sense of competition and resentment among studio instructors. Another wrote "Too many students per studio faculty. Not enough time to adequately teach." These responses suggest 

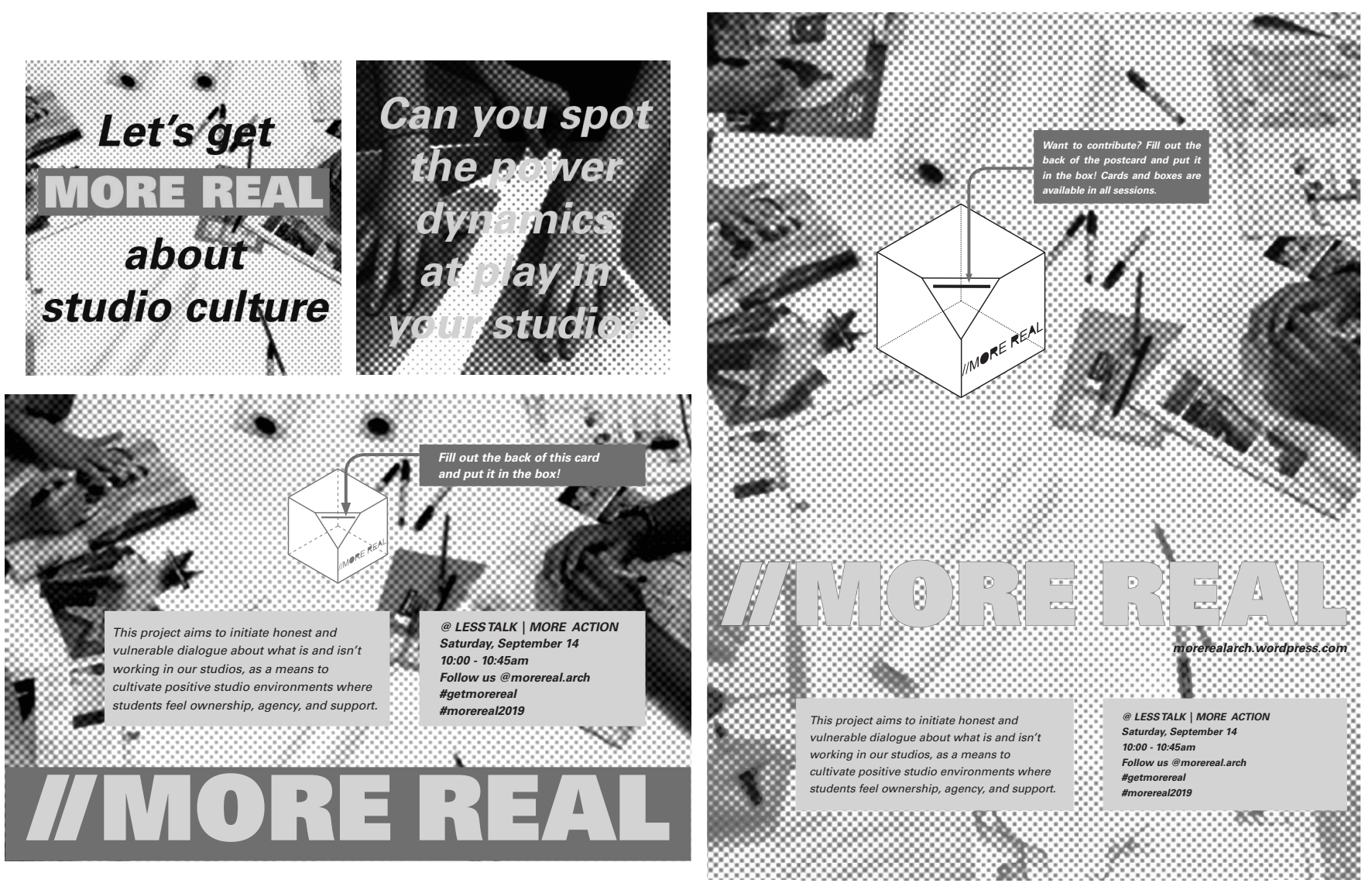

Figure 4: A selection of MORE REAL graphics: Instagram posts, postcards, and conference poster.

that future surveys should explicitly ask about the administrative and institutional dynamics that impact studio culture.

Several respondents wrote that the increasing role of computers in the studio (along with students increasingly commuting to school, rather than living on campus) contributes to a sense of disconnection and lack of community among students. One respondent wrote that students at their commuter school "preferred to work from home almost strictly digitally. This fundamental difference I think is one detrimental element to their education and particularly the sense of community that is formed by working in studio. The collective energy of students I think lends itself to students having more ownership over their space, their work, and support for one another." Another wrote, "with all students doing more work on laptops there is less need for them to be in the studio so they are not as invested in the studio culture. It's also not helped by more students living off-campus and not in the neighborhood of the school so less time is spent at studio outside of class time. I think this leads to less healthy competition as well as peer discussion and critique." An instructor teaching an online comprehensive design studio wrote that "it felt too removed and too much like working in an office. I don't feel that it fostered enough free-thinking, but rather a method of administrating the class' projects' progress." These responses raise an important question: as online learning becomes increasingly popular at universities across the United States, how can instructors foster supportive relationships and constructive dialog among their students? The authors wonder whether students are already ahead of their instructors in addressing this question, since many students actively communicate via social media platforms, often without their studio instructor's knowledge.

A significant number (six) of the respondents discussed the ways that studio culture has changed since they were students. Of these, almost all wrote about increased diversity and more inclusive culture: "When I was in school 20 years ago almost all faculty were white and male;" "As a student very much master/student. At my current university more open-more process-oriented-still jury system-but more open + inclusive;" "Elite and expensive, a long time ago so the discussion was different than now-but so many were left out of the discussion - starting with women;" "Different from when I was a student. Much more inclusive, experimental, open and responsive."

Only one respondent wrote at length about diversity and inclusion in the present. The response raises profound questions about how studio culture must change to address a 
more diverse student body, which is impacted and shaped by growing social, racial, and economic inequality and unequal access to education even before the students enter architecture school:

The student body is more diverse than it has ever been. The economic and demographic diversity has been great. But the diversity also includes the skill-sets, accumulated knowledge, and capacity for learning that students enter with, from high school. In accordance with national trends, there is no middle class left. Our best students are better than ever-the product of elite high school education, private tutoring, academic summer camps. Our lower-end students are lower than ever, due to the failures of the general public school systems. While a small minority excels, and is avid for more, the general curve is downhill. (For example, 15 years ago, we could ask that students read two medium-length articles a week for a theory course. Today, anything more than one short article yields failures. And studio readings have become inconceivable).

Rather than help level the field, their college experience only accentuates the disparities. The few who entered in the lead will continue on to graduate school and exit even further ahead. Those who took out heavy loans in the belief of the opportunities yielded by a college degree will not only never catch up, but will be burdened with debts incompatible with the current economy.

As an instructor, it is incredibly difficult to navigate this studio environment. Do we consciously not teach to the elite? Teaching to the middle has become useless when there's no middle left-it's both over the majority's head, and unchallenging for the minority. To not leave anyone behind also means to disqualify all of them from the competitiveness of the world they're about to enter. I see this increasing trend as a pedagogical challenge that should be addressed with urgency.

\section{CONVERSATION AT THE ACSA SESSION}

At the MORE REAL ACSA session, 20 participants came to discuss the survey and results. We structured the session around reading the survey responses, beginning with a short introduction of our process and intention for the session, and stressing that this session was meant to be the beginning of the MORE REAL project. The conference session allowed participants to connect with the experiences that had been shared. As participants read anonymous responses aloud, everyone shared a laugh with a young man as he began to read a response that started, "20 years ago when I was in school..." After reading responses, participants formed small groups of about 4-5 people for short, 10-minute-long conversations. Groups were asked to share highlights from their conversations about the responses, as well as their own experiences of studio culture.
Topics that emerged were student-focused and primarily faculty-controlled. They focused on the role of faculty and structure of studio. One group discussed shifting student demographics and the resultant divisions within studio that an influx of international students has brought. They suggested faculty to be trained to help unite divisions between students. Another group made a case for a bottom-up approach that challenges the long-held values and priorities of architectural pedagogy, urging faculty to develop more humane studio culture practices-as architecture is a human-centered occupation. Groups discussed time management in the context of the all-nighter and 24-hour building access, which they argued are further complicated by faculty expectations and student perception. The entire group discussed ways to limit 24-hour access, the lengths students might go to have access, and how this might exclude students who work or have families. Groups discussed studio structures, potentials for student representation, and shifting the jury format from evaluation to speculation. Multiple groups stressed the need to move beyond design as the most important part of architectural education. All groups emphasized faculty responsibility in setting studio culture and the importance of faculty as a collaborative facilitator.

Some aspects the session structure worked better than others. For instance, participants enjoyed reading anonymous responses aloud, as well as breaking into smaller groups for discussion. Some of the nuanced and fine-grained details of the small group conversations were lost with the report-out method used. In future iterations, it would be worthwhile to request that groups individually perform live-notetaking for their entire conversation in order to preserve the nuance of shared ideas.

\section{CONCLUSION}

MORE REAL set out to uncover what is going on in architecture studios by asking faculty to share their studio culture experiences though a simple, open-ended survey. This yielded interesting results, as we collected many interpretations of "your studio culture experience." We have learned that, to understand studio culture from the faculty perspective, we must consider how we ask respondents to share their story; many recalled their past experiences as students and not their current experiences as faculty. Future iterations of the survey will explicitly ask respondents to share their experiences as a student as well as a faculty member. Faculty seemed reluctant to share their own negative teaching experiences; instead they were shared positive teaching experiences and negative experiences from when they were students.

For this initial iteration of MORE REAL, we promoted the project through cohesively branded digital and print collateral (Figures 4-5). Prior to the conference, we emailed the survey to colleagues and set up a website and Instagram account to drive survey participation. At the conference, we handed out 


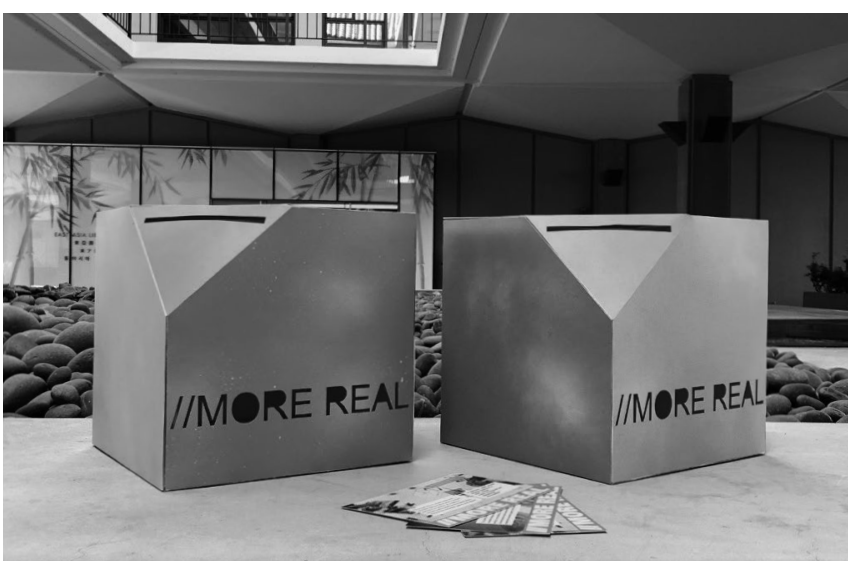

Figure 5: MORE REAL submission boxes at the Less Talk | More Action Conference.

printed survey cards to engage attendees and promote survey participation. We set up survey collection boxes in strategic locations throughout the venue for the duration of the conference. To our surprise, we received more responses from the physical survey cards and direct contact with conference attendees than we did from emailing the survey to our own contacts. We believe that this may be for a number of reasons, including the participatory nature of attendees at this conference, the social dynamic of talking with attendees and handing out physical survey cards, and the role that the branded cards and boxes played as physical reminders to participate. We found our aspirations for engagement were sometimes at odds with the decentralized nature of the conference and campus environment

\section{NEXT SURVEY ITERATION}

The authors acknowledge that both the small sample size and the lack of diversity in respondents, the majority of whom were white, ${ }^{5}$ middle-class and identified as female, ${ }^{6}$ fail to represent the true range of studio culture experiences. In order to counteract this, we plan to develop strategies for reaching a more broadly representative group in future iterations. The survey should expand to engage students, administrators, practitioners, and alumni from architecture programs who have chosen to pursue another career. Future surveys should pick up on broad themes that emerged from the responses. They could ask about administrative and institutional dynamics that impact studio culture, or ask respondents to share alternative review formats that challenge the jury format. A question could investigate the role of collaboration and competition as it pertains to the quality of student experience. The notion of studio culture could be broadened to include its influence on practice, as architecture firms grapple with similar issues (for example, work-life balance).

In order to expand the survey while maintaining simplicity and ease of participation, we will need to develop a streamlined process for participating that uses more specific prompts with short answer responses. We will likely add check boxes to gain greater insight into the respondent's path through school and any support structures they may have used along the way. In expanding the survey to include these support structures, MORE REAL can benefit from cross-pollination with the other session we led at the Less Talk | More Action conference, Working Group: Strategies and Tactics to foster a more inclusive architectural pedagogy. Working Group seeks to identify and develop strategies for dismantling the many barriers that stand in the way of students becoming an architect, and asks how studio culture must change to address a more diverse student body, which is impacted and shaped by growing social, racial, and economic inequality and unequal access to education even before students enter architecture school.

\section{ENDNOTES}

1. The National Architectural Accrediting Board, 2018 Annual Report on Architectural Education, 2018, https://www.naab.org/wp-content/ uploads/2018_NAAB-Annual-Report.pdf.

2. Ibid. We were able to compare survey data on gender and ethnicity to the NAAB 2018 Annual Report on Architectural Education, but NAAB does not publish data on sexual orientation or socioeconomic background.

3. Ibid.

4. The NAAB Conditions for Accreditation define studio culture as "a positive and respectful learning environment that encourages optimism, respect, sharing, engagement, and innovation between and among the members of its faculty, student body, administration, and staff in all learning environments, both traditional and nontraditional." "AIAS and NAAB Partner to Promote Healthy Studio Culture," AIAS News (April 11, 2018). http://www.aias.org/ aias-and-naab-partner-to-promote-healthy-studio-culture.

5. Considering that the NAAB 2018 Annual Report states that $72 \%$ of all faculty (including adjuncts) teaching at an accredited institution indicated white for their ethnicity, the overall lack of diversity among architecture faculty is likely contributing to the lack of diversity of survey respondents. The National Architectural Accrediting Board, 2018 Annual Report on Architectural Education, 2018, https://www.naab.org/wp-content/uploads/2018_NAABAnnual-Report.pdf.

6. A study conducted in 2008 regarding online survey participation found that female faculty were more likely to respond than their male counterparts. "Chi square analysis comparing respondent and sample frame data revealed that a significantly larger percentage of female faculty members returned surveys than did their male counterparts..." William Smith, "Does Gender Influence Online Survey Participation? A Record-Linkage Analysis of University Faculty Online Survey Response Behavior," ERIC (Institute of Education Services) (2008): https://files.eric.ed.gov/fulltext/ED501717.pdf. 